\title{
Resistant hypertension
}

\author{
Fang-Fei Wei ${ }^{1}$, Zhen-Yu Zhang ${ }^{1,2,3}$, Qi-Fang Huang ${ }^{1,4}$, Wen-Yi Yang ${ }^{1}$, Jan A. Staessen ${ }^{1,5}$ \\ 1Studies Coordinating Centre, Research Unit Hypertension and Cardiovascular Epidemiology, KU Leuven Department of \\ Cardiovascular Diseases, University of Leuven, Leuven, Belgium \\ ${ }^{2}$ Institut universitaire de médicine sociale et préventive, University of Lausanne, Lausanne, Switzerland \\ ${ }^{3}$ Department of Cardiovascular Diseases, Shanghai General Hospital, Shanghai, China \\ ${ }^{4}$ Centre for Epidemiological Studies and Clinical Trials and Centre for Vascular Evaluations, Shanghai Institute of Hypertension, \\ Shanghai Key Laboratory of Hypertension, Ruijin Hospital, Shanghai Jiaotong University School of Medicine, Shanghai, China \\ ${ }^{5}$ Cardiovascular Research Institute Maastricht (CARIM), Maastricht University, Maastricht, Netherlands
}

\begin{abstract}
The publication of the first non-randomised proof-of-concept trial of renal denervation as a treatment modality in treatment-resistant hypertension set the stage for a search for novel devices with the expectation that technology would reduce the burden of hypertension by reducing or eliminating the costly and lifelong use of blood pressure-lowering medications. As we demonstrate in this review, this idea was so attractive to manufacturers and invasive cardiologists and radiologists that they overlooked decades of careful pathophysiological research in a disease that remains enigmatic but is still a major cause of cardiovascular mortality worldwide. To make our point, we first reviewed the prevalence and risks associated with treatment-resistant hypertension. Next, we highlighted the key points required for the diagnosis of treatment-resistant hypertension, including the recording of ambulatory blood pressure and the assessment of adherence to medication. Finally, we summarised new insights in the management of treatment-resistant hypertension by medication and devices as well as in future research. Throughout our review, we focused on new evidence that had become available since 2013. Our conclusion is that optimising medical treatment based on simple algorithms remains the state of the art in treatment-resistant hypertension.
\end{abstract}

Key words: resistant hypertension, pharmacology, sympathetic nervous system, baroreflex, renal denervation

Kardiol Pol 2018; 76, 7: 1031-1042

\section{INTRODUCTION}

Hypertension remains the predominant driver of cardiovascular disease, which is the leading cause of morbidity and mortality worldwide [1]. Resistant hypertension is a seated office blood pressure (BP) of at least $140 \mathrm{mmHg}$ systolic or $90 \mathrm{mmHg}$ diastolic in patients on a maximally tolerated dose of three or more antihypertensive agents, one of which must be a diuretic $[2,3]$. In addition, some guidelines recommend that the daytime ambulatory BP should be at least $135 \mathrm{mmHg}$ systolic or $85 \mathrm{mmHg}$ diastolic on the same regimen [2-4] to exclude white-coat hypertension. Thus, true resistant hypertension refers to a diagnosis of essential hypertension with exclusion of all other potential causes of uncontrolled BP, including secondary hypertension, pseudo-resistance due to poor adherence, or the white-coat effect $[2,3]$.
Resistant hypertension is more likely to occur in patients with increased sympathetic drive, such as obesity, diabetes, or renal dysfunction [5-8]. Resistant hypertensive patients are at high risk of cardiovascular complications [9, 10]. Until recently, treatment options included lifestyle interventions, intensified pharmacological treatment, renal denervation, and stimulation of carotid sinus. In our review, we will highlight the progress made from the state of the art in 2013 [3]. We will focus on recent studies on the prevalence, risk, diagnosis, and management of resistant hypertension, limitations of the current evidence, and propose directions for future research.

\section{EPIDEMIOLOGY}

Most epidemiological studies lack key components for ascertaining the presence of resistant hypertension, such as medica-

\section{Address for correspondence:}

Jan A. Staessen, MD, PhD, Studies Coordinating Centre, Research Unit Hypertension and Cardiovascular Epidemiology, KU Leuven Department of Cardiovascular Diseases, University of Leuven, Campus Sint Rafaël, Kapucijnenvoer 35, Box 7001, BE-3000 Leuven, Belgium, e-mail: jan.staessen@med.kuleuven.be; ja.staessen@maastrichtuniversity.nl Received: 06.06.2018 Accepted: 06.06.2018 Available as AoP: 06.06.2018 
tion adherence and ambulatory BP measurement. The ideal design to estimate the prevalence of true resistant hypertension would be a large prospective cohort study of hypertensive patients with BP control ascertained by ambulatory monitoring after forced titration up to full doses of three different classes of hypertensive medications, including a diuretic. However, such a prospective study has not yet been published. Recently, the prevalence of resistant hypertension is estimated mainly from observational studies and outcome-based clinical trials.

\section{Prevalence}

The prevalence of hypertension in previous studies is highly variable, ranging from $9 \%$ to $18 \%$, due to divergent diagnostic approaches and the non-exclusion of pseudo-resistant hypertension. In a meta-analysis of 961,035 individuals, the prevalence of resistant hypertension was $13.7 \%$ (95\% confidence interval $[\mathrm{Cl}] 11.2-16.2)$ in 20 observational studies and $16.3 \%(95 \% \mathrm{Cl} 10.7-21.9)$ in four randomised clinical trials, but pseudo-resistance caused by suboptimal drug dosing, poor medication adherence, and the white-coat effect could not be ruled out [11]. Of 68,045 patients enrolled in the Spanish Ambulatory Blood Pressure Monitoring Registry, 8295 (12.2\%) had resistant hypertension based on having an increased office BP while on treatment with three or more antihypertensive drugs, including a diuretic, but the prevalence decreased to 5184 (7.6\%) after white-coat hypertension had been excluded [12]. In the MINISAL-SIIA survey, representative for 47 Italian centres, investigators excluded secondary and white-coat hypertension. The prevalence of resistant hypertension among patients on stable drug therapy was $8.2 \%$ and increased 1.5 -fold per one standard deviation increase in age and body mass index. However, accounting for an appropriate lifestyle, as exemplified by a 24-h urinary sodium excretion below $100 \mathrm{mmol}$ and a normal body mass index, reduced the prevalence to $0.8 \%$ [13].

\section{Associated risks}

In a retrospective analysis of two integrated health care plans in the United States, the incidence of resistant hypertension among 24,499 patients was $1.9 \%$ within 1.5 years (median) from initial treatment with a rate of 0.7 cases per 100 patient-years of follow-up [10]. Patients with resistant hypertension had higher rates of baseline diabetes $(17.7 \%$ vs. 9.6\%) compared to those with non-resistant hypertension. In multivariable-adjusted analyses, the hazard ratio (HR) for incidental adverse cardiovascular outcomes over 3.8 years (median) associated with resistant hypertension was 1.47 (95\% Cl 1.33-1.62) [10]. Four recent studies strengthened the evidence associating resistant hypertension with adverse health outcomes [7, 14-16], but only one [7] applied ambulatory BP monitoring to exclude pseudo-resistance and none assessed treatment adherence. Among 14,684 patients randomised in the Antihypertensive and Lipid-Lowering to Prevent Heart Attack Trial (ALLHAT) [15], the multivariable-adjusted HRs as- sociated with apparent resistant hypertension vs. non-resistant hypertension were $1.30(95 \% \mathrm{Cl} 1.11-1.52)$ for all-cause mortality, $1.44(95 \% \mathrm{Cl} 1.18-1.76)$ for coronary heart disease, 1.88 (95\% Cl 1.52-2.34) for heart failure, 1.57 (95\% $\mathrm{Cl} 1.18-2.08)$ for stroke, and $1.95(95 \% \mathrm{Cl} 1.11-3.41)$ for end-stage renal disease. Among 470,386 individuals enrolled in the Kaiser Permanente Southern California health care programme [16], these HRs, respectively, were 1.06 (95\% $\mathrm{Cl} 1.03-1.08), 1.24$ (95\% Cl 1.20-1.28), $1.46(95 \% \mathrm{Cl}$ 1.40-1.52), 1.14 (95\% Cl 1.10-1.19), and $1.32(95 \% \mathrm{Cl}$ 1.27-1.37). Among 1911 treated hypertensive patients, the $\mathrm{HR}$ of all cardiovascular events contrasting patients with persistent hypertension vs. never having resistant hypertension was 2.22 (95\% Cl 1.21-4.05) [14]. In a study of 436 patients with chronic kidney disease and a diagnosis of office hypertension [7], the HR for renal events ( $n=165)$, compared to true normotension as reference, was 1.24 (95\% Cl 0.55-2.78) for white-coat hypertension, 1.11 (95\% Cl 0.67-1.84) for sustained hypertension, and 1.98 (95\% Cl 1.14-3.43) for truly resistant hypertension.

\section{DIAGNOSIS}

In a review published in 2012 [17], we highlighted several diagnostic criteria that need to be fulfilled to ascertain the presence of treatment-resistant hypertension. Foremost, secondary hypertension should be excluded, using procedures that fall beyond the scope of this review but are outlined in current guidelines [4].

\section{Blood pressure measurement}

The time has come to revise the diagnosis of resistant hypertension by making ambulatory BP measurement a condicio sine qua non. The United States Preventive Services Task Force [18], the United Kingdom National Institute for Health and Clinical Excellence [19], the European Society of Hypertension [20], and the Canadian Hypertension Education Programme [21] carefully examined the evidence as to which method of BP measurement is best. All of them forcefully recommended ambulatory BP monitoring as the method of choice [18-21]. The greater number of readings, the absence of digit preference and observer bias, and the minimisation of the white-coat effect all contribute to the prognostic superiority of ambulatory over office BP [22, 23]. The major contribution of ambulatory BP monitoring to risk stratification is the cross-classification between office and ambulatory BP in untreated people [24] as well as in treated patients [25]. In clinical practice, the commonly used definition of white-coat hypertension is a raised in-office $\mathrm{BP}$ in the presence of a normal daytime ambulatory BP. Results of event-driven studies convincingly demonstrated that the risk of cardiovascular disease is lower in patients with white-coat hypertension than in those with raised ambulatory BP, even after controlling for concomitant risk factors [26]. 
Self-measured BP at home shares some of the advantages of ambulatory $\mathrm{BP}$, such as the greater number of readings and the identification of the white-coat effect [27]. However, home BP measurement cannot replace 24-h ambulatory monitoring as the gold standard to exclude pseudo-resistant hypertension. For instance, using home instead of ambulatory monitoring misses the high-risk diagnoses of masked or sustained hypertension in over $25 \%$ of patients [28]. Thus, $24-\mathrm{h}$ ambulatory monitoring is the cornerstone in diagnosing and managing resistant hypertension, although it might be alternated with self-measurement at home in optimising drug treatment [27].

\section{Adherence}

As already reported 30 years ago [29] and confirmed since then in numerous studies [30, 31], drug adherence is a major problem in patients with resistant hypertension. Drugs do not work in patients who do not take them. Non-adherence is therefore a major cause of pseudo-resistance and should always be assessed in treatment-resistant hypertension. Indirect methods to evaluate drug adherence are vulnerable to biases or misclassification and amongst others include pill counts, interviews with patients, self-reported drug use, pharmacodynamic signs such as heart rate on $\beta$-blockers, or reactive activation of the renin-angiotensin-aldosterone axis on treatment with angiotensin-converting enzyme inhibitors or blockers of the angiotensin I type- 1 receptor. Scores of 8,7 to 6 , and less than 6 obtained by administering the eight-item Morisky Medication Adherence Scale [32] signify high, medium, and low adherence, respectively. Rates of prescription refills are readily available to obtain objective data, but require a closed pharmacy system and do not allow evaluating whether the prescribed drugs were truly taken [33]. The same applies to electronic medication monitors that produce quantifiable results and track patterns of taking medication [31], but require return visits, repackaging drugs, and expensive technology. Objective methods include witnessed drug intake [34] and measuring drugs or their metabolites in body fluids [35].

To our knowledge, only four trials of renal denervation in treatment-resistant hypertension [34, 36-38] applied a stringent approach to assess adherence. In the Oslo trial (NCT01673516) [34], 19 of 65 screened patients (29.2\%) were excluded from randomisation because ambulatory BP normalised after witnessed drug intake just before the qualifying visit. In the Renal Denervation for Hypertension Trial (DENERHTN; NCT01570777) [36] drug adherence was assessed at the six-month visit in 85 of 106 randomised patients $(80.2 \%)$ by determining the urinary $\mathrm{N}$-acetyl-seryl-aspartyl-lysyl-proline/creatinine ratio [39] and by ultra-high-performance liquid chromatography tandem mass spectrometry to detect the drugs in urine or plasma [35]. The prevalence of nonadherence in DENERHTN was comparable in both treatment groups, amounting to approximately $50 \%$. The Renal Sympathetic Denervation as a New Treatment for Therapy-Resistant
Hypertension Trial (SYMPATHY; NCT01850901) [37] and the Investigator-Steered Project on Intravascular Denervation for Management of Treatment-Resistant Hypertension (INSPiRED; NCT01505010) [38] are the only trials of renal denervation in which drug adherence was assessed by measuring drug concentrations at baseline and follow-up. In 78 of 139 (56.1\%) patients randomised in SYMPATHY, blood samples were drawn synchronously with BP measurements. Neither patients nor physicians knew that adherence was being monitored. In $80 \%$ of patients, fewer medications were detected than prescribed, and adherence changed during follow-up in $31 \%$ of patients [37]. In the INSPiRED pilot trial [38], nonadherence was observed in four of nine (44\%) patients randomised to control and in three of six (50\%) allocated to renal denervation. Nonadherence at any time from baseline to the six-month visit occurred in eight (88.9\%) patients vs. four (66.7\%), respectively, randomised to control or renal denervation. In the SPYRAL HTN-OFF MED trial (NCT02439749) [40], overall compliance with the requirement to be off antihypertensive medications in 80 patients from baseline until the three-month visit was $85.5 \%$.

Poor adherence is not only a cause of pseudo-resistant hypertension but is also an indicator of poor prognosis [41, 42]. A database maintained by 400 Italian primary care physicians included 18,806 newly diagnosed hypertensive patients, aged 35 years or more, who were initially free of cardiovascular disease [41]. Adherence was subdivided a priori into three categories: high (proportion of days covered by filled prescriptions $\geq 80 \%$ ), intermediate $(40 \%-79 \%)$, and low $(<40 \%)$ [43]. Six months after the index diagnosis, $8.1 \%$, $40.5 \%$, and $51.4 \%$ of patients were classified as having high, intermediate, and low adherence levels, respectively. The composite cardiovascular endpoint consisted of first-ever acute coronary syndromes, angina pectoris, and cerebrovascular events also including transient ischaemic attack. Over 4.6 years of follow-up, the crude incidence of the composite endpoint was 7.4, 8.4, and 7.5 per 1000 patient-years, for low, intermediate, and high adherers, respectively. After statistical modelling and cumulative adjustments for confounders, the HR associated with high vs. low adherence was 0.62 (95\% Cl 0.40-0.96; $p=0.032$ ) [41].

Patients with resistant hypertension can adhere better to medication with the use of educational measures and behavioural interventions targeted to overcome the resistance to treatment $[2,44]$. However, more than $50 \%$ of patients with refractory hypertension remained non-compliant with medications when blood and urine levels were measured [37, 38, 40]. Renal denervation trials confirm that: (1) poor drug adherence is a frequent cause of apparently resistant and difficult-to-treat hypertension, (2) drug adherence is a dynamic phenomenon influenced by complex psychosocial determinants and cannot be captured by any single assessment, and (3) changes in drug adherence are a major 


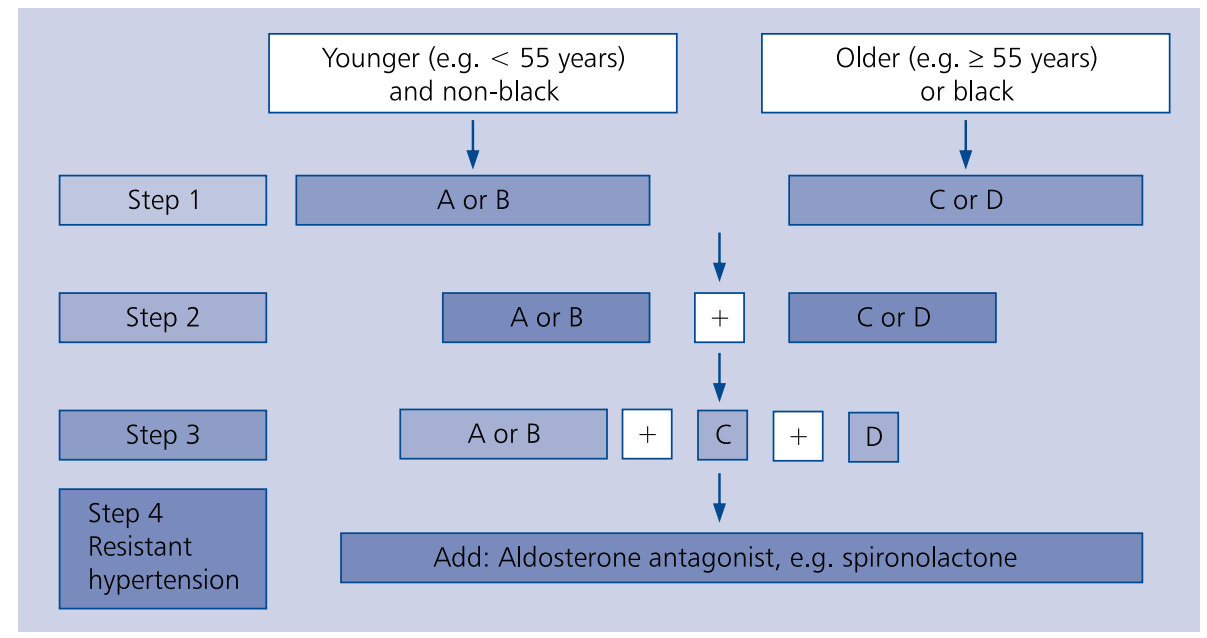

Figure 1. Recommendation for combining blood-pressure lowering drugs according to the AB/CD rule. Modified from [49]; A - angiotensin-converting enzyme inhibitors or angiotensin receptor blockers; $\mathrm{B}-\beta$-blockers; $\mathrm{C}-$ calcium-channel blockers; D - diuretic (thiazide/thiazide-like)

potential confounder in trials assessing new treatment modalities of resistant hypertension [45]. These findings highlight the necessity to address adherence as described in the next section of our review.

\section{MANAGEMENT}

Renal sympathetic nerves play an important role in regulating BP. The efferent sympathetic nervous outflow to the kidney stimulates renin release, promotes sodium and water retention, and reduces renal blood flow [46]. Sympathetic nervous drive to the kidney is increased in hypertensive patients, particularly in resistant hypertension [47]. Other contributing causes of resistant hypertension include chronic kidney disease, hyperaldosteronism, and obstructive sleep apnoea [48]. The approach to the management of resistant hypertension, confirmed by ambulatory BP monitoring and assessment of adherence, should be comprehensive and include lifestyle measures and management of risk factors as reviewed elsewhere $[2,44]$.

\section{Medical treatment}

Optimising pharmacological treatment of confirmed treatment-resistant hypertension rests on a few simple principles: (i) use of combinations of antihypertensive drugs with different mode of action in line with the AB/CD algorithm [49] (Fig. 1), which in contrast to voluminous multipage guidelines is easily understandable for physicians who are not hypertension specialists [49]; (ii) use of antihypertensive agents with a long duration of action based on their molecular structure rather than on their galenic formulation, the so-called "forgiving drugs" [50]; (iii) up-titration of each drug to the highest dose that does not produce side-effects; (iv) inclusion of a diuretic in the drug combination; (v) once the right combination has been found by rotation through and combining drug classes, stimulation of adherence by reducing the pill load through prescription of single-pill combination tablets including two or three antihypertensive agents in adjustable doses [31]; and (vi) attempting use of aldosterone receptor antagonists or $\beta$-blockers if not contraindicated.

Consistent with the notion that resistant hypertension is common in patients with primary hyperaldosteronism, mineralocorticoid receptor antagonists provide significant benefit in lowering BP when added to existing multidrug regimens [51-53]. The strongest evidence to support the use of aldosterone receptor blockers originates from the recently published PATHWAY-2 trial (NCT 02369081). In this double-blind, placebo-controlled, crossover trial 335 patients were randomly assigned to sequential treatment with spironolactone, doxazosin, bisoprolol, and placebo [54]. Eligibility criteria included: age ranging from 18 to 79 years, a seated clinic systolic pressure of $140 \mathrm{mmHg}$ (135 mmHg in diabetic patients) or greater, a home systolic blood pressure (SBP; 18 readings over four days) of $130 \mathrm{mmHg}$ or greater, and treatment for at least three months with the maximally tolerated doses of three antihypertensive agents. The average reduction in home SBP by spironolactone was $8.7 \mathrm{mmHg}$ superior to placebo (95\% Cl 7.7-9.7 $\mathrm{mmHg}$ ), $4.3 \mathrm{mmHg}$ superior to the mean of the other two active treatments (doxazosin and bisoprolol; 95\% Cl 3.4-5.1 mmHg), $4.0 \mathrm{mmHg}$ superior compared to doxazosin $(95 \% \mathrm{Cl} 3.0-5.0 \mathrm{mmHg}$ ), and $4.5 \mathrm{mmHg}$ superior to bisoprolol $(95 \% \mathrm{Cl} 3.5-5.5 \mathrm{mmHg})$. Spironolactone was the most effective blood-pressure lowering treatment throughout the distribution of baseline plasma renin, but its margin of superiority and likelihood of being the best drug for the individual patient were greater in the lower than higher ends of the plasma renin distribution. In only six of 285 patients who received spironolactone, serum potassium exceeded $6.0 \mathrm{mmol} / \mathrm{L}$ on a single occasion [54], suggesting 
that spironolactone can be administered without excessive risk of hyperkalaemia.

Amiloride antagonises the epithelial sodium channel in the distal collecting duct of the kidney and functions as an indirect aldosterone antagonist. In a blinded comparison, amiloride 10 mg daily, spironolactone 25 mg daily, or a combination of both were used as add-on therapy in African-American patients whose BP was uncontrolled on a two-drug regimen consisting of a diuretic (a thiazide diuretic in $92 \%$ of patients and a loop diuretic in the remaining $8 \%$ ) and a calcium channel blocker [53]. The mean decreases in SBP and diastolic blood pressure (DBP) compared with placebo were, respectively, $12.2 \mathrm{mmHg}$ and $4.8 \mathrm{mmHg}$ for amiloride, $7.3 \mathrm{mmHg}$ and $3.3 \mathrm{mmHg}$ for spironolactone, and $14.1 \mathrm{mmHg}$ and $5.1 \mathrm{mmHg}$ for the combination [53]. The most common adverse effect of spironolactone is breast tenderness with or without breast enlargement, particularly in men. If this occurs, amiloride is an alternative to spironolactone.

Arterial vasodilators, such as the potassium-channel opener minoxidil [55] or the selective endothelin type A antagonist darusentan [56], are other options to be considered in treatment-resistant hypertension in countries where these drugs are registered. However, fluid retention, oedema occurring in over $25 \%$ of patients [56], focal necrosis of the papillary heart muscle [55] and subendocardial areas of the left ventricle [56], arrhythmia [55, 56], pericardial effusion [55], and heart failure $[55,56]$ limit their clinical application to patients in whom other treatment options failed.

Guidelines fall short in describing how BP must be followed up in patients with treatment-resistant hypertension. However, the same principles apply as for the use of ambulatory monitoring for the diagnosis of treatment-hypertension. After each optimisation step of the drug regimen, ambulatory monitoring may be repeated within two to three weeks to determine if adequate BP reduction has been achieved. If further adjustments in therapy are required, as may often be the case, then it is justifiable to repeate ambulatory monitoring at two-to-three-week intervals, until control is achieved. Once the daytime and nighttime BPs are controlled, ambulatory monitoring must only be repeated at three-month to six-month intervals. Self-measurement of BP at home can be used to obtain confirmatory evidence that the awake BP control is maintained [57]. To obtain a self-measured BP equivalent to the daytime ambulatory $\mathrm{BP}$, six days of measurement are required, two readings in the morning and two in the evening, after discarding the measurements from the first day. The average of the 24 remaining readings should be less than $135 \mathrm{mmHg}$ systolic and less than $85 \mathrm{mmHg}$ diastolic $[22,23]$.

\section{Device-based treatment}

\section{Renal denervation}

In 2009, the non-randomised proof-of-concept SYMPLICITY HTN-1 trial (NCT 00483808 and NCT 00664638) showed that percutaneous radiofrequency catheter-based renal sympathet- ic nervous denervation was feasible, effective, and safe [58]. Among 45 analysed patients enrolled in this first-in-human open study, on treatment with 4.5 antihypertensive drugs, SBP/DBP at entry was $177 / 101 \mathrm{mmHg}$ and decreased by 27/17 mmHg 12 months after renal denervation [58]. After the proof-of-concept study, the open SIMPLICITY HTN-2 trial (NCT00888433) [59] enrolled treatment-resistant patients whose BP on treatment with 5.2 drugs was 178/98 $\mathrm{mmHg}$. Office BP decreased by $32 / 12 \mathrm{mmHg}$ in the denervation group and did not change in control patients. In the subsequent single-blind sham-controlled SYMPLICITY HTN-3 trial (NCT01418261) [60], the primary and secondary efficacy endpoints were the changes in systolic pressure at six months, as assessed by office and 24-h ambulatory monitoring, respectively. The decreases in systolic pressure in the denervation $(n=364)$ compared with the control $(n=171)$ group were $14.1 \mathrm{mmHg}$ vs. $11.7 \mathrm{mmHg}$ and $6.8 \mathrm{mmHg}$ vs. $4.8 \mathrm{mmHg}$ on office and ambulatory monitoring, respectively, resulting in baseline-adjusted intergroup differences of $2.4 \mathrm{mmHg}$ $(95 \% \mathrm{Cl} 2.1-6.9 \mathrm{mmHg} ; \mathrm{p}=0.26)$ and $2.0 \mathrm{mmHg}(95 \% \mathrm{Cl}$ -1.0-5.0 mmHg; $p=0.98$ ) [60]. SYMPLICTY HTN-3 [60] and other trials reporting similarly disappointing [37, 61-66] or borderline significant [67] results, even if all of them confirmed the safety of the procedure, shattered the prospect of bringing renal denervation to clinical application in treatment-resistant hypertension (Fig. 2). Of note, among the randomised clinical trials (Fig. 2), only WAVE IV (NCT02029885) [66] applied externally delivered ultrasound energy to sever the renal nerves. All other trials [37, 38, 58-66] used an intraarterial approach to deliver radiofrequency energy. A randomised trial using intravascularly delivered ultrasound energy is ongoing (RADIANCE-HTN; NCT02649426) and expected to report in 2018. A study showing the feasibility of a new endovascular approach to renal denervation, using chemical necrolysis via periadventitial infusion of dehydrated alcohol (ethanol), still needs to be followed up by a properly designed randomised clinical trial.

One notable exception to the aforementioned disappointing results was the INSPiRED pilot trial, which after the publication of SYMPLICITY HTN-3 received ethical clearance to randomise 18 patients [38]. Three Belgian hypertension centres screened 29 patients on treatment with three drugs or more, of whom 17 after optimisation of treatment were randomised and 15 were analysed six months later, while medical treatment was continued $(n=9)$ or combined with renal denervation by the EnligHTN ${ }^{\mathrm{TM}}$ multi-electrode system $(\mathrm{n}=6)$. The baseline-adjusted systolic/diastolic differences amounted to $19.5 / 10.4 \mathrm{mmHg}$ (change in control vs. intervention group, +7.6/+2.2 vs. $-11.9 /-8.2 \mathrm{mmHg} ; \mathrm{p}=0.088)$ for office BP and 22.4/13.1 mmHg (+0.7/+0.3 vs. -21.7/-12.8; $\mathrm{mmHg}$; $\mathrm{p}$ 0.049) for 24-h BP (Fig. 2), the primary efficacy endpoint. At six months electrocardiogram voltages and the number of prescribed drugs ( $p \leq 0.036)$ were lower in renal denervation patients, but quality of life and adherence cap- 


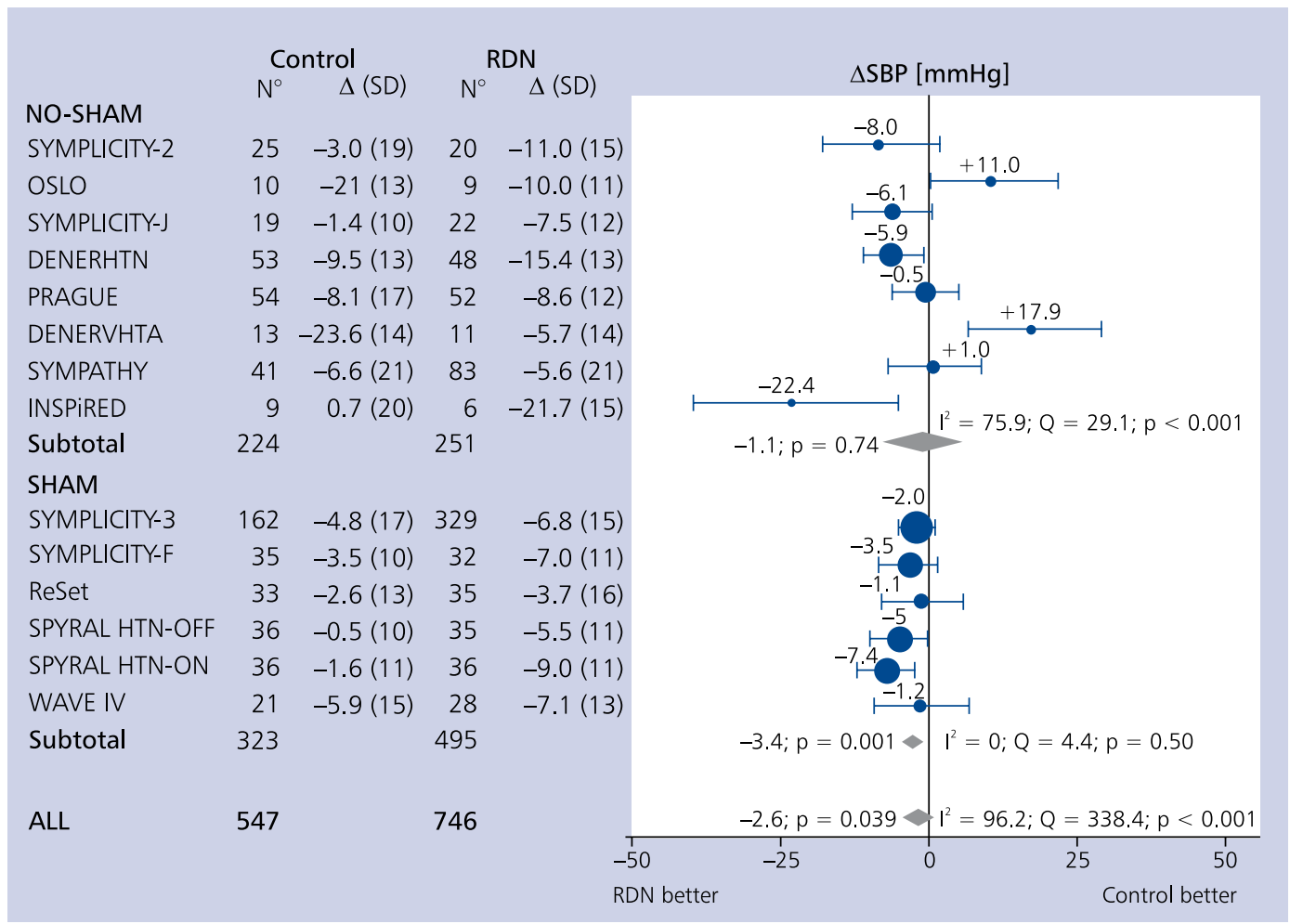

Figure 2. Change in 24-h systolic blood pressure $(\triangle \mathrm{SBP})$ in patients randomised to renal denervation (RDN) or control in eight studies without sham control and in five sham-controlled studies. Solid points represent the point estimate in individual studies and have a size proportional to the inverse of the variance. Horizontal lines and diamonds denote the $95 \%$ confidence intervals for individual studies and pooled estimates, respectively. P-values refer to the significance of the pooled intergroup estimate and Cochran's Q test for heterogeneity. For $\mathrm{I}^{2}$, values $<25 \%, 25 \%-50 \%$, and $>50 \%$ indicate modest, moderate, and substantial heterogeneity, respectively

tured by measuring drug levels in urine were similar in both groups [38].

In view of the disappointing results of renal denervation in patients with treatment resistant-hypertension, manufactures changed tactics, turned to untreated hypertensive patients or treated patients with mild hypertension, and shortened follow-up from six to three months. The SPYRAL HTN-OFF MED study (NCT02439749) evaluated the effect of renal denervation on $\mathrm{BP}$ in the absence of antihypertensive medications [40]. Eligible patients were drug-naïve (90\%) or discontinued their antihypertensive medications for three to four weeks (10\%) and had an SBP ranging from $150 \mathrm{mmHg}$ to $180 \mathrm{mmHg}$ and from $140 \mathrm{mmHg}$ to $170 \mathrm{mmHg}$ on office and 24-h ambulatory monitoring, respectively, and an office DBP of $90 \mathrm{mmHg}$ or more. They were randomly assigned to renal denervation ( $n=38$ ) or sham control $(n=42)$. Office and 24-h ambulatory SBP/DBP decreased significantly ( $\mathrm{p} \leq 0.003$ ) from baseline to three months by $10.0 / 5.3 \mathrm{mmHg}$ and by $5.5 / 4.8 \mathrm{mmHg}$ in the renal denervation and control group, respectively, resulting in mean baseline-adjusted differences of 7.7/4.9 mmHg (95\% Cl 1.5-14.0 mmHg/-1.4-8.5 mmHg; $\mathrm{p} \leq 0.016)$ on office measurement and $5.0 / 4.4 \mathrm{mmHg}(95 \%$
Cl 0.2-9.9 mmHg/1.6-7.2 mmHg; $\mathrm{p} \leq 0.041$ ) on ambulatory monitoring [40]. Our take on these results is that regulatory authorities would not approve any antihypertensive drug if its blood pressure-lowering effects were of a similar order of magnitude as observed in the SPYRAL HTN-OFF MED study [40]. The investigators therefore rightfully concluded that given the current state of knowledge regarding renal denervation, one could not confidently claim or endorse catheter-based renal denervation beyond an investigational technology [40]. The SPYRAL-HTN ON-MED trial (NCT02439775) has a similar design as SPYRAL HTN OFF-MED but requires patients to be treated with a consistent triple drug antihypertensive regimen [68]. As reported very recently [68], at 6 months, the mean baseline-adjusted differences were $6.8 / 3.5 \mathrm{mmHg}$ (1.1-12.5 mmHg/0-7.0 mmHg) for office BP and 7.4/4.1 mmHg (2.3 12.5 mmHg/0.4-7.8 mmHg) for 24-h BP in favour of the renal denervation group $(p \leq 0.048)$.

\section{Baroreflex activation therapy}

Electrical stimulation of the carotid baroreceptors acutely decreased arterial BP in patients with resistant hypertension by sympathetic inhibition [69]. The Device-Based Therapy 
in Hypertension Trial (DEBuT-HT; NCT00710190) [70] was a non-randomised feasibility study in 45 patients with stage-two office hypertension while on treatment with at least two antihypertensive agents. After three months and two years, office SBP/DBP decreased by $21 / 12 \mathrm{mmHg}$ and $33 / 22 \mathrm{mmHg}$, respectively [70]. The Rheos Pivotal Trial (NCT00442286) [71] was a double-blind randomised trial in 265 patients with resistant hypertension. All patients had a baroreceptor-stimulating device implanted and were subsequently randomised to immediate stimulation $(n=181)$ or stimulation delayed until six months after device implantation $(n=84)$. The primary endpoint was the change in the office BP at six months as measured by an automated oscilometric device [71]. Responders had a decrease in SBP of at least $10 \mathrm{mmHg}$. At six months, there were $54 \%$ and $46 \%$ responders in the stimulated and control group, respectively $(p=0.005)$, which did not represent a significant difference with the $20 \%$ superiority margin $(p=0.97)$. At six months SBP decreased by $16 \mathrm{mmHg}$ vs. $9 \mathrm{mmHg}$ in the stimulated and control group ( $p=0.08$ ), and at 12 months it was similar in both groups, averaging $25 \mathrm{mmHg}$. Thus, although safety criteria were met, the study failed to meet its primary efficacy endpoint [71].

With technology advancing, two other studies reported on the efficacy of carotid baroreceptor stimulation. The Barostim neo trial (NCT01679132) was a single-arm, open-label study in 30 patients with resistant hypertension [72]. The new carotid baroreceptor-stimulating device was designed to work with a single electrode implanted unilaterally, making the surgical procedure much simpler. Office SBP/DBP reduction was $26 / 12 \mathrm{mmHg}$ at six months [72]. A subsequent single-arm study [73] reported a decrease $(p<0.01)$ in the 24-h BP six months after device implantation, from $148 \mathrm{mmHg}$ to $140 \mathrm{mmHg}$ systolic and from $82 \mathrm{mmHg}$ to $77 \mathrm{mmHg}$ diastolic. A recent publication [74] combined data from the DEBuT-HT $(n=45)$ [70], the US Rheos Feasibility trial (NCT01077180; $\mathrm{n}=16$ ) [75], and the Rheos Pivotal Trial $(n=322)$ [71]. Altogether, 383 patients were available for analysis; 143 of these had completed five years of follow-up, and 48 patients had completed six years of follow-up. In the entire cohort, office BP fell $(p<0.001)$ from $179 \mathrm{mmHg}$ to $144 \mathrm{mmHg}$ systolic, and from $103 \mathrm{mmHg}$ to $85 \mathrm{mmHg}$ diastolic [74]. In $25 \%$ of patients, the median number of medications decreased from six to three [74]. Overall, the evidence supporting carotid baroreceptor stimulation as a treatment modality in resistant hypertension remains unconvincingly weak. The most important limitations are the single-arm unblinded design of most studies $[70,72,73,75$, 76] with the exception of the first six months of follow-up in the Rheos Pivotal Trial [71], failure to meet the primary efficacy endpoint in the Rheos Pivotal Trial [71], variable follow-up duration, use of office rather than 24-h ambulatory monitoring [70-72, 74-76], the lack of reliable data on adherence, and the possible influence of the nocebo (Hawthorne) effect [77].

\section{Arteriovenous anastomosis}

The novel arteriovenous ROX Coupler (ROX Medical, San Clemente, CA, USA) reduces BP by adding a low-resistance high-compliance venous segment to the central arterial tree [78]. An open-label randomised trial assessed the efficacy of this approach in patients with uncontrolled hypertension [79]. Eligible patients had a baseline office SBP of $140 \mathrm{mmHg}$ or higher and an average daytime ambulatory BP of $135 \mathrm{mmHg}$ systolic and $85 \mathrm{mmHg}$ diastolic or higher, despite antihypertensive treatment. The primary endpoint was the mean change from baseline in office and 24-h ambulatory SBPs at six months [79]. Mean office SBP decreased by $26.9 \mathrm{mmHg}$ from $175 \mathrm{mmHg}$ in the arteriovenous coupler group $(\mathrm{n}=44)$ and by $3.7 \mathrm{mmHg}$ from $171 \mathrm{mmHg}(\mathrm{n}=39)$ in the control group. Mean 24-h SBP declined by $13.5 \mathrm{mmHg}$ from $157 \mathrm{mmHg}$ in the intervention group and by $0.5 \mathrm{mmHg}$ from $156 \mathrm{mmHg}$ in controls [79]. The baseline-adjusted intergroup differences were significant $(p<0.001)$. Replication of this small trial remains necessary. Another major limitation is that the technique is associated with the development of symptomatic venous stenosis. Although this complication can be managed with conventional strategies, the long-term safety remains a matter of major concern.

\section{PERSPECTIVES FOR THE FUTURE}

From our review of the literature, two points emerged as possible new avenues for future research.

\section{Design of future trials}

Our review revealed that poor insight in the pathophysiological mechanism raising BP and weak design features explain why most trials of devices to treat resistant hypertension failed to reach their efficacy endpoints. Renal denervation is certainly based on sound evidence on the role of the sympathetic nervous system [80, 81] and the kidneys [82] in hypertension and represents a major leap forward compared with the unselective sympatholytic surgery as practiced from the 1930s until the 1980s [83]. However, assuming that renal denervation would be efficacious in a large number of patients with a variety of conditions was overly optimistic. In rats, transplantation of a kidney from a hypertensive to a normotensive animal produces hypertension, although by definition the transplanted kidney is not innervated [82]. Moreover, essential hypertension is characterised by generalised membrane abnormalities, which could affect the function of the vasculature and many organs in various ways [84]. Isolated systolic hypertension in seniors is caused by stiffening of the large arteries and not by an increased sympathetic tone [85]. These concepts underline that selection of patients with essential hypertension for enrolment in future trials not only requires 
exclusion of pseudo-resistance by ambulatory BP monitoring and checking of adherence to an optimised drug regimen, but also an assessment of the extent to which hypertension is dependent on volume overloading and sodium retention as opposed to increased peripheral arterial resistance, the hallmark of increased sympathetic tone. Non-invasive estimation of systemic arterial resistance requires measurement of cardiac index and mean arterial pressure. Furthermore, one cannot expect that treatment-resistant patients with severe target organ damage will be responsive to renal denervation. The European Network Coordinating Research on Renal Denervation (ENCOReD) demonstrated that worse renal function at baseline was associated with a lower probability of improvement in the 24-h BP (odds ratio [OR] for $20-\mu \mathrm{mol} / \mathrm{L}$ increase in serum creatinine, $0.60 ; p=0.05$ ) and higher probability of experiencing no BP decrease (OR 1.66; $p=0.01$ ) [86].

Patients with accessory arteries that cannot be engaged for renal denervation should not be enrolled in trials [87], although they might still benefit from the procedure. The $\mathrm{BP}$ and heart rate responses to renal nerve stimulation might provide a procedural endpoint indicating effective renal denervation and might identify the anatomical localisation within the renal arterial system to be preferentially denervated [88]. We hope that rolling renal denervation out to untreated patients or treated patients with mild hypertension will not stop manufacturers from supporting clinical trials in highly selected patients with truly resistant hypertension, in whom all other treatment options failed, but who represent a much smaller number of clients and therefore a less profitable market.

\section{Biomarkers}

Another hopeful development that has been shaping up over the past decade is the introduction in clinical practice of circulating, urinary metabolic, or proteomic biomarkers, which provide insight in the pathophysiology of hypertension and which are associated with early target organ damage at a time when prevention remains possible, long before irreversible organ failure sets in. Circulating desphospho-uncarboxylated matrix Gla protein (dp-ucMGP) is a marker of vitamin $\mathrm{K}$ status [89]. Active MGP is a strong local inhibitor of vascular calcifications [89] and helps maintain the integrity of the renal microcirculation [90, 91]. Mucin-1 is a high-molecular-weight (400 kDa), heavily O-glycosylated, type-I membrane-tethered glycoprotein [92]. Normal kidneys express mucin-1 in the thick segment of Henle's loop and in the distal tubules and collecting ducts [92]. The main function of mucin-1 is to shield cell surfaces by maintenance of a luminal epithelial mucobarrier [92]. The $\mathrm{N}$-terminal $\alpha$-subunit of mucin- 1 is shed when renal function starts to decline. Both circulating dp-ucMGP [91] and urinary mucin-1 [93] might be tested in treatment-resistant hypertension for the early detection of patients at the greatest risk of irreversible kidney damage. The same applies to CKD273, a multidimensional urinary classifier consisting of 273 peptide fragments. The American Food and Drug Administration recently encouraged further studies of CKD273 as a tool for diagnosis and risk prediction in chronic kidney disease [94]. CKD273 not only predicts deterioration of renal dysfunction [95], and earlier than micro-albuminuria does [96], but it is also a forerunner of adverse cardiovascular complications [95]. HF1 and HF2 are urinary proteomic classifiers, respectively consisting of 85 and 671 peptides, predictive of imminent diastolic left ventricular dysfunction and the incidence of cardiovascular complications $[97,98]$. A recent study suggests that urinary markers of the citric acid metabolism might predict the treatment response to spironolactone in patients with treatment-resistant hypertension [99]. Our view on the future is that the use of these omics technologies, after proper validation in randomised clinical trials [100], will revolutionise selection of patients with resistant hypertension for the treatment options which are already currently available or are becoming part of the clinical armamentarium in the future, thereby giving these patents access to a personalised approach.

\section{CONCLUSIONS}

Once the diagnosis of resistant hypertension is confirmed, optimisation of drug treatment remains the cornerstone of its management. For now, device treatment should remain the ultima ratio in adherent and truly resistant patients with severe hypertension, in whom all other efforts to reduce BP have failed. The intervention should only be offered to patients within a context of clinical research in highly skilled tertiary referral centres. Future research should focus on a better understanding of the intrinsic (in the patients) and extrinsic (e.g. environmental stressors) mechanisms that contribute to an adherent patient's irresponsiveness to blood pressure-lowering drugs. Biomarkers predictive of target organ damage and new technologies, such as renal nerve stimulation, might help in selecting the few patients who might benefit from device therapy.

Funding: The European Union (HEALTH-F7-305507-HOMAGE), the European Research Council (Advanced Researcher Grant 2011-294713-EPLORE and Proof-of-Concept Grant 713601-uPROPHET), the European Research Area Net for Cardiovascular Diseases (JTC2017-046-PROACT), and the Fonds voor Wetenschappelijk Onderzoek Vlaanderen, Ministry of the Flemish Community, Brussels, Belgium (G.0881.13) currently support the Studies Coordinating Centre in Leuven.

\section{Conflict of interest: none declared}

\section{References}

1. Lopez AD, Mathers CD, Ezzati M, et al. Global and regional burden of disease and risk factors, 2001: systematic analysis of population health data. Lancet. 2006; 367(9524): 1747-1757, doi: 10.1016/S0140-6736(06)68770-9, indexed in Pubmed: 16731270 . 
2. Calhoun DA, Jones D, Textor S, et al. Resistant hypertension: diagnosis, evaluation, and treatment: a scientific statement from the American Heart Association Professional Education Committee of the Council for High Blood Pressure Research. Circulation. 2008; 117(25): e510-e526, doi: 10.1161/CIRCULATIONAHA.108.189141, indexed in Pubmed: 18574054.

3. Sarafidis PA, Georgianos P, Bakris GL. Resistant hypertension - its identification and epidemiology. Nat Rev Nephrol. 2013; 9(1): 51-58, doi: 10.1038/nrneph.2012.260, indexed in Pubmed: 23165303.

4. Mancia G, Fagard R, Narkiewicz K, et al. 2013 ESH/ESC guidelines for the management of arterial hypertension: the Task Force for the Management of Arterial Hypertension of the European Society of Hypertension (ESH) and of the European Society of Cardiology (ESC). Eur Heart J. 2013; 34(28): 2159-2219, doi: 10.1093/eurheartj/eht151, indexed in Pubmed: 23771844.

5. Bramlage P, Pittrow D, Wittchen HU, et al. Hypertension in overweight and obese primary care patients is highly prevalent and poorly controlled. Am J Hypertens. 2004; 17(10): 904-910, doi: 10.1016/j.amjhyper.2004.05.017, indexed in Pubmed: 15485752.

6. Solini A, Zoppini G, Orsi E, et al. Resistant hypertension in patients with type 2 diabetes: clinical correlates and association with complications. J Hypertens. 2014; 32(12): 2401-10; discussion 2410, doi: 10.1097/HJH.0000000000000350, indexed in Pubmed: 25198422.

7. De Nicola L, Gabbai FB, Agarwal R, et al. Prevalence and prognostic role of resistant hypertension in chronic kidney disease patients. J Am Coll Cardiol. 2013; 61(24): 2461-2467, doi: 10.1016/j. jacc.2012.12.061, indexed in Pubmed: 23623908.

8. Iftikhar IH, Valentine CW, Bittencourt LRA, et al. Effects of continuous positive airway pressure on blood pressure in patients with resistant hypertension and obstructive sleep apnea: a meta-analysis. J Hypertens. 2014; 32(12): 2341-2350; discussion 2350, doi: 10.1097/HJH.0000000000000372, indexed in Pubmed: 25243523.

9. Persell SD. Prevalence of resistant hypertension in the United States, 2003-2008. Hypertension. 2011; 57(6): 1076-1080, doi 10.1161/HYPERTENSIONAHA.111.170308, indexed in Pubmed: 21502568.

10. Daugherty SL, Powers JD, Magid DJ, et al. Incidence and prognosis of resistant hypertension in hypertensive patients. Circulation. 2012; 125(13): 1635-1642, doi: 10.1161/CIRCULATIONAHA.111.068064, indexed in Pubmed: 22379110.

11. Achelrod D, Wenzel U, Frey S. Systematic review and meta-analysis of the prevalence of resistant hypertension in treated hypertensive populations. Am J Hypertens. 2015; 28(3): 355-361, doi: 10.1093/ajh/hpu151, indexed in Pubmed: 25156625.

12. de la Sierra A, Segura J, Banegas JR, et al. Clinical features of 8295 patients with resistant hypertension classified on the basis of ambulatory blood pressure monitoring. Hypertension. 2011 57(5): 898-902, doi: 10.1161/HYPERTENSIONAHA.110.168948, indexed in Pubmed: 21444835.

13. Galletti F, Barbato A. MINISAL-SIIA Study Group. Prevalence and determinants of resistant hypertension in a sample of patients followed in Italian hypertension centers: results from the MINISAL-SIIA study program. J Hum Hypertens. 2016; 30(11): 703-708, doi: 10.1038/jhh.2016.6, indexed in Pubmed: 26935287.

14. Tsioufis C, Kasiakogias A, Kordalis A, et al. Dynamic resistant hypertension patterns as predictors of cardiovascular morbidity: a 4-year prospective study. J Hypertens. 2014; 32(2): 415-422, doi: 10.1097/HJH.0000000000000023, indexed in Pubmed: 24241057.

15. Muntner P, Davis BR, Cushman WC, et al. Treatment-resistant hypertension and the incidence of cardiovascular disease and end-stage renal disease: results from the Antihypertensive and Lipid-Lowering Treatment to Prevent Heart Attack
Trial (ALLHAT). Hypertension. 2014; 64(5): 1012-1021, doi: 10.1161/HYPERTENSIONAHA.114.03850, indexed in Pubmed: 25259745.

16. Sim JJ, Bhandari SK, Shi J, et al. Comparative risk of renal, cardiovascular, and mortality outcomes in controlled, uncontrolled resistant, and nonresistant hypertension. Kidney Int. 2015; 88(3): 622-632, doi: 10.1038/ki.2015.142, indexed in Pubmed: 25945406.

17. Persu A, Renkin J, Thijs L, et al. Renal denervation: ultima ratio or standard in treatment-resistant hypertension. Hypertension. 2012; 60(3): 596-606, doi: 10.1161/HYPERTENSIONAHA.112.195263, indexed in Pubmed: 22851728.

18. Siu A. on behalf of the U.S.Preventive Services Task Force. Screening for High Blood Pressure in Adults: U.S. Preventive Services Task Force Recommendation Statement. Ann Intern Med. 2015; 163(10): 778, doi: 10.7326/m15-2223, indexed in Pubmed: 26458123.

19. National Institute for Health and Clinical Excellence (NICE). Hypertension in adults: diagnosis and management. https://www. nice.org.uk/guidance/cg127 (updated Nov 2016).

20. O'Brien E, Parati G, Stergiou G, et al. European Society of Hypertension position paper on ambulatory blood pressure monitoring. J Hypertens. 2013; 31(9): 1731-1768, doi: 10.1097/HJH.0b013e328363e964, indexed in Pubmed: 24029863 .

21. Leung AA, Nerenberg K, Daskalopoulou SS, et al. Hypertension Canada's 2016 Canadian Hypertension Education Program Guidelines for Blood Pressure Measurement, Diagnosis, Assessment of Risk, Prevention, and Treatment of Hypertension. Can J Cardiol. 2016; 32(5): 569-588, doi: 10.1016/j.cjca.2016.02.066, indexed in Pubmed: 27118291.

22. O'Brien E, Asmar R, Beilin L, et al. European Society of Hypertension recommendations for conventional, ambulatory and home blood pressure measurement. J Hypertens. 2003; 21(5): 821-848, doi: 10.1097/00004872-200305000-00001.

23. O'Brien E, Asmar R, Beilin L, et al. Practice guidelines of the European Society of Hypertension for clinic, ambulatory and self blood pressure measurement. J Hypertens. 2005; 23(4): 697-701, doi: 10.1097/01.hjh.0000163132.84890.c4, indexed in Pubmed: 15775768.

24. Franklin SS, Thijs L, Asayama K, et al. The Cardiovascular Risk of White-Coat Hypertension. J Am Coll Cardiol. 2016; 68(19): 2033-2043, doi: 10.1016/j.jacc.2016.08.035, indexed in Pubmed: 27810041.

25. Clement DL, De Buyzere ML, De Bacquer DA, et al. Prognostic value of ambulatory blood-pressure recordings in patients with treated hypertension. N Engl J Med. 2003; 348(24): 2407-2415, doi: 10.1056/NEJMoa022273, indexed in Pubmed: 12802026.

26. Asayama K, Li Y, Franklin SS, et al. Cardiovascular Risk Associated With White-Coat Hypertension: Con Side of the Argument. Hypertension. 2017; 70(4): 676-682, doi: 10.1161/HYPERTENSIONAHA.117.08902, indexed in Pubmed: 28847889.

27. Staessen JA, Li Y, Hara A, et al. Blood pressure measurement anno 2016. Am J Hypertens. 2017; 30(5): 453-463, doi: 10.1093/ajh/hpw148, indexed in Pubmed: 28052877.

28. Zhang Lu, Li Y, Wei FF, et al. Strategies for classifying patients based on office, home, and ambulatory blood pressure measurement. Hypertension. 2015; 65(6): 1258-1265, doi: 10.1161/HYPERTENSIONAHA.114.05038, indexed in Pubmed: 25870194.

29. Gifford RW. An algorithm for the management of resistant hypertension. Hypertension. 1988; 11(3 Pt 2): II101-II105, doi: 10.1161/01.HYP.11.3_Pt_2.II101, indexed in Pubmed: 3350593.

30. Schmieder RE, Ott C, Schmid A, et al. Adherence to Antihypertensive Medication in Treatment-Resistant Hypertension Undergoing Renal Denervation. J Am Heart Assoc. 2016; 5(2), doi: 10.1161/JAHA.115.002343, indexed in Pubmed: 26873693. 
31. Burnier M, Wuerzner G, Struijker-Boudier H, et al. Measuring, analyzing, and managing drug adherence in resistant hypertension. Hypertension. 2013; 62(2): 218-225, doi: 10.1161/HYPERTENSIONAHA.113.00687, indexed in Pubmed: 23753412.

32. Morisky DE, Ang A, Krousel-Wood M, et al. Predictive validity of a medication adherence measure in an outpatient setting. J Clin Hypertens. 2008; 10(5): 348-354, indexed in Pubmed: 18453793.

33. Osterberg L, Blaschke T. Adherence to medication. N Engl J Med. 2005; 353(5): 487-497, doi: 10.1056/NEJMra050100, indexed in Pubmed: 16079372.

34. Fadl Elmula FE, Hoffmann P, Fossum E, et al. Renal sympathetic denervation in patients with treatment-resistant hypertension after witnessed intake of medication before qualifying ambulatory blood pressure. Hypertension. 2013; 62(3): 526-532, doi: 10.1161/HYPERTENSIONAHA.113.01452, indexed in Pubmed: 23836798.

35. Jung O, Gechter JL, Wunder C, et al. Resistant hypertension? Assessment of adherence by toxicological urine analysis. J Hypertens. 2013; 31(4): 766-774, doi: 10.1097/HJH.0b013e32835e2286, indexed in Pubmed: 23337469.

36. Azizi M, Pereira H, Hamdidouche I, et al. Adherence to Antihypertensive Treatment and the Blood Pressure-Lowering Effects of Renal Denervation in the Renal Denervation for Hypertension (DENERHTN) Trial. Circulation. 2016; 134(12): 847-857, doi: 10.1161/CIRCULATIONAHA.116.022922, indexed in Pubmed: 27576780 .

37. de Jager RL, de Beus E, Beeftink MMA, et al. Impact of Medication Adherence on the Effect of Renal Denervation: The SYMPATHY Trial. Hypertension. 2017; 69(4): 678-684, doi: 10.1161/HYPERTENSIONAHA.116.08818, indexed in Pubmed: 28264922.

38. Jacobs L, Persu A, Huang QF, et al. Results of a randomized controlled pilot trial of intravascular renal denervation for management of treatment-resistant hypertension. Blood Press. 2017; 26(6): 321-331, doi: 10.1080/08037051.2017.1320939, indexed in Pubmed: 28489464.

39. Azizi M, Ménard J, Peyrard S, et al. Assessment of patients' and physicians' compliance to an ACE inhibitor treatment based on urinary N-acetyl Ser-Asp-Lys-Pro determination in the Noninsulin-Dependent Diabetes, Hypertension, Microalbuminuria, Proteinuria, Cardiovascular Events, and Ramipril (DIABHYCAR) study. Diabetes Care. 2006; 29(6): 1331-1336, doi: 10.2337/dc060255, indexed in Pubmed: 16732017.

40. Townsend RR, Mahfoud F, Kandzari DE, et al. Catheter-based renal denervation in patients with uncontrolled hypertension in the absence of antihypertensive medications (SPYRAL HTN-OFF MED): a randomised, sham-controlled, proof-of-concept trial. Lancet. 2017; 390(10108): 2160-2170, doi: 10.1016/S0140-6736(17)32281-X, indexed in Pubmed: 28859944.

41. Mazzaglia G, Ambrosioni E, Alacqua M, et al. Adherence to antihypertensive medications and cardiovascular morbidity among newly diagnosed hypertensive patients. Circulation. 2009; 120(16): 1598-1605, doi: 10.1161/CIRCULATIONAHA.108.830299, indexed in Pubmed: 19805653.

42. Corrao G, Parodi A, Nicotra F, et al. Better compliance to antihypertensive medications reduces cardiovascular risk. J Hypertens. 2011; 29(3): 610-618, doi: 10.1097/HJH.0b013e328342ca97, indexed in Pubmed: 21157368.

43. Rasmussen JN, Chong A, Alter DA. Relationship between adherence to evidence-based pharmacotherapy and long-term mortality after acute myocardial infarction. J Am Med Ass. 2007 297(2): 177-186, doi: 10.1001/jama.297.2.177, indexed in Pubmed: 17213401

44. Shimbo D, Levitan EB, Booth JN, et al. The contributions of unhealthy lifestyle factors to apparent resistant hypertension: findings from the Reasons for Geographic And Racial Differences in Stroke (REGARDS) study. J Hypertens. 2013; 31(2):
370-376, doi: 10.1097/HJH.0b013e32835b6be7, indexed in Pubmed: 23303356.

45. Berra E, Azizi M, Capron A, et al. Evaluation of adherence should become an integral part of assessment of patients with apparently treatment-resistant hypertension. Hypertension. 2016; 68(2): 297-306, doi: 10.1161/HYPERTENSIONAHA.116.07464, indexed in Pubmed: 27296995.

46. DiBona GF, Kopp UC. Neural control of renal function. Physiol Rev. 1997; 77(1): 75-197, doi: 10.1152/physrev.1997.77.1.75, indexed in Pubmed: 9016301.

47. Tsioufis C, Kordalis A, Flessas D, et al. Pathophysiology of resistant hypertension: the role of sympathetic nervous system. Int J Hypertens. 2011; 2011: 642416, doi: 10.4061/2011/642416, indexed in Pubmed: 21331155.

48. Faselis C, Doumas M, Papademetriou V. Common secondary causes of resistant hypertension and rational for treatment. Int J Hypertens. 2011; 2011: 236239, doi: 10.4061/2011/236239, indexed in Pubmed: 21423678.

49. British Cardiac Society, British Hypertension Society, Diabetes UK, HEART UK, Primary Care Cardiovascular Society, Stroke Association. JBS 2: Joint British Societies' guidelines on prevention of cardiovascular disease in clinical practice. Heart. 2005; 91 Suppl 5: v1-52, doi: 10.1136/hrt.2005.079988, indexed in Pubmed: 16365341.

50. Hernández-Hernández R, Armas de Hernández MJ, Armas-Padilla MC, et al. The effects of missing a dose of enalapril versus amlodipine on ambulatory blood pressure. Blood Press Monit. 1996; 1(2): 121-126, indexed in Pubmed: 10226213.

51. Ouzan J, Pérault C, Lincoff AM, et al. The role of spironolactone in the treatment of patients with refractory hypertension. Am J Hypertens. 2002; 15(4 Pt 1): 333-339, indexed in Pubmed: 11991219

52. Nishizaka MK, Zaman MA, Calhoun DA. Efficacy of low-dose spironolactone in subjects with resistant hypertension. Am J Hypertens. 2003; 16(11 Pt 1): 925-930, indexed in Pubmed: 14573330

53. Saha C, Eckert GJ, Ambrosius WT, et al. Improvement in blood pressure with inhibition of the epithelial sodium channel in blacks with hypertension. Hypertension. 2005; 46(3): 481-487, doi: 10.1161/01.HYP.0000179582.42830.1d, indexed in Pubmed: 16116042

54. Williams B, MacDonald TM, Morant S, et al. Spironolactone versus placebo, bisoprolol, and doxazosin to determine the optimal treatment for drug-resistant hypertension (PATHWAY-2): a randomised, double-blind, crossover trial. Lancet. 2015; 386(10008): 2059-2068, doi: 10.1016/S0140-6736(15)00257-3, indexed in Pubmed: 26414968.

55. Campese VM. Minoxidil: a review of its pharmacological properties and therapeutic use. Drugs. 1981; 22(4): 257-278, indexed in Pubmed: 7030707.

56. Weber MA, Black H, Bakris G, et al. A selective endothelin-receptor antagonist to reduce blood pressure in patients with treatment-resistant hypertension: a randomised, double-blind, placebo-controlled trial. Lancet. 2009; 374(9699): 1423-1431, doi: 10.1016/S0140-6736(09)61500-2, indexed in Pubmed: 19748665

57. Sheppard JP, Stevens R, Gill P, et al. Predicting out-of-office blood pressure in the clinic (PROOF-BP): derivation and validation of a tool to improve the accuracy of blood pressure measurement in clinical practice. Hypertension. 2016; 67(5): 941-950, doi: 10.1161/HYPERTENSIONAHA.115.07108, indexed in Pubmed: 27001299.

58. Krum H, Schlaich M, Whitbourn R, et al. Catheter-based renal sympathetic denervation for resistant hypertension: a multicentre safety and proof-of-principle cohort study. Lancet. 2009; 373(9671): 1275-1281, doi: 10.1016/S0140-6736(09)60566-3, indexed in Pubmed: 19332353. 
59. Esler MD, Krum H, Sobotka PA, et al. Symplicity HTN-2 Investigators. Renal sympathetic denervation in patients with treatment-resistant hypertension (The Symplicity HTN-2 Trial): a randomised controlled trial. Lancet. 2010; 376(9756): 1903-1909, doi: 10.1016/S0140-6736(10)62039-9, indexed in Pubmed: 21093036.

60. Bhatt DL, Kandzari DE, O'Neill WW, et al. A controlled trial of renal denervation for resistant hypertension. N Engl J Med. 2014; 370(15): 1393-1401, doi: 10.1056/NEJMoa1402670, indexed in Pubmed: 24678939.

61. Fadl Elmula FE, Hoffmann P, Larstorp AC, et al. Adjusted drug treatment is superior to renal sympathetic denervation in patients with true treatment-resistant hypertension. Hypertension. 2014; 63(5): 991-999, doi: 10.1161/HYPERTENSIONAHA.114.03246, indexed in Pubmed: 24591332.

62. Rosa J, Widimský P, Waldauf P, et al. Renal denervation in comparison with intensified pharmacotherapy in true resistant hypertension: 2-year outcomes of randomized PRAGUE-15 study. J Hypertens. 2017; 35(5): 1093-1099, doi: 10.1097/HJH.0000000000001257, indexed in Pubmed: 28118281

63. Oliveras A, Armario $\mathrm{P}$, Clarà $\mathrm{A}$, et al. Spironolactone versus sympathetic renal denervation to treat true resistant hypertension: results from the DENERVHTA study - a randomized controlled trial. J Hypertens. 2016; 34(9): 1863-1871, doi: 10.1097/HJH.0000000000001025, indexed in Pubmed: 27327441.

64. Desch S, Okon T, Heinemann D, et al. Randomized sham-controlled trial of renal sympathetic denervation in mild resistant hypertension. Hypertension. 2015; 65(6): 1202-1208, doi: 10.1161/HYPERTENSIONAHA.115.05283, indexed in Pubmed: 25824248.

65. Mathiassen ON, Vase H, Bech JN, et al. Renal denervation in treatment-resistant essential hypertension. A randomized, SHAM-controlled, double-blinded 24-h blood pressure-based trial. J Hypertens. 2016; 34(8): 1639-1647, doi: 10.1097/HJH.0000000000000977, indexed in Pubmed: 27228432 .

66. Schmieder RE, Ott C, Toennes SW, et al. Phase II randomized sham-controlled study of renal denervation for individuals with uncontrolled hypertension - WAVE IV. J Hypertens. 2018; 36(3): 680-689, doi: 10.1097/HJH.0000000000001584, indexed in Pubmed: 29035942.

67. Azizi M, Sapoval M, Gosse P, et al. Optimum and stepped care standardised antihypertensive treatment with or without renal denervation for resistant hypertension (DENERHTN): a multicentre, open-label, randomised controlled trial. Lancet. 2015 385(9981): 1957-1965, doi: 10.1016/S0140-6736(14)61942-5, indexed in Pubmed: 25631070.

68. Kandzari DE, Böhm M, Mahfoud F, et al. Effect of renal denervation on blood pressure in the presence of antihypertensive drugs: 6-month efficacy and safety results from the SPYRAL HTN-ON MED proof-of-concept randomised trial. Lancet. 2018; 391(10137): 2346-2355, doi: 10.1016/S0140-6736(18)30951-6, indexed in Pubmed: 29803589.

69. Heusser K, Tank J, Engeli S, et al. Carotid baroreceptor stimulation, sympathetic activity, baroreflex function, and blood pressure in hypertensive patients. Hypertension. 2010; 55(3): 619-626, doi: 10.1161/HYPERTENSIONAHA.109.140665, indexed in Pubmed: 20101001.

70. Scheffers IJM, Kroon AA, Schmidli J, et al. Novel baroreflex activation therapy in resistant hypertension: results of a European multi-center feasibility study. J Am Coll Cardiol. 2010; 56(15): 1254-1258, doi: 10.1016/j.jacc.2010.03.089, indexed in Pubmed: 20883933.
71. Bisognano J, Bakris G, Nadim M, et al. Baroreflex Activation Therapy Lowers Blood Pressure in Patients With Resistant Hypertension. J Am Coll Cardiol. 2011; 58(7): 765-773, doi: 10.1016/j. jacc.2011.06.008, indexed in Pubmed: 21816315.

72. Hoppe UC, Brandt MC, Wachter R, et al. Minimally invasive system for baroreflex activation therapy chronically lowers blood pressure with pacemaker-like safety profile: results from the Barostim neo trial. J Am Soc Hypertens. 2012; 6(4): 270-276, doi: 10.1016/j.jash.2012.04.004, indexed in Pubmed: 22694986.

73. Wallbach M, Lehnig LY, Schroer C, et al. Effects of Baroreflex Activation Therapy on Ambulatory Blood Pressure in Patients With Resistant Hypertension. Hypertension. 2016; 67(4): 701-709, doi: 10.1161/HYPERTENSIONAHA.115.06717, indexed in Pubmed: 26902491.

74. de Leeuw PW, Bisognano JD, Bakris GL, et al. Sustained reduction of blood pressure with baroreceptor activation therapy: results of the 6-year open follow-up. Hypertension. 2017; 69(5): 836-843, doi: 10.1161/HYPERTENSIONAHA.117.09086, indexed in Pubmed: 28320856.

75. Illig KA, Levy M, Sanchez L, et al. An implantable carotid sinus stimulator for drug-resistant hypertension: surgical technique and short-term outcome from the multicenter phase II Rheos feasibility trial. J Vasc Surg. 2006; 44(6): 1213-1218, doi: 10.1016/j. jvs.2006.08.024, indexed in Pubmed: 17145423.

76. Bakris GL, Nadim MK, Haller H, et al. Baroreflex activation therapy provides durable benefit in patients with resistant hypertension: results of long-term follow-up in the Rheos Pivotal Trial. J Am Soc Hypertens. 2012; 6(2): 152-158, doi: 10.1016/j. jash.2012.01.003, indexed in Pubmed: 22341199.

77. Colloca L, Finniss D. Nocebo effects, patient-clinician communication, and therapeutic outcomes. J Am Med Ass. 2012; 307(6): 567-568, doi: 10.1001/jama.2012.115, indexed in Pubmed: 22318275.

78. Korsheed S, Eldehni MT, John SG, et al. Effects of arteriovenous fistula formation on arterial stiffness and cardiovascular performance and function. Nephrol Dial Transplant. 2011; 26(10): 3296-3302, doi: 10.1093/ndt/gfq851, indexed in Pubmed: 21317408.

79. Lobo MD, Sobotka PA, Stanton A, et al. Central arteriovenous anastomosis for the treatment of patients with uncontrolled hypertension (the ROX CONTROL HTN study): a randomised controlled trial. Lancet. 2015; 385(9978): 1634-1641, doi: 10.1016/S01406736(14)62053-5, indexed in Pubmed: 25620016.

80. Kingwell BA, Thompson JM, Kaye DM, et al. Heart rate spectral analysis, cardiac norepinephrine spillover, and muscle sympathetic nerve activity during human sympathetic nervous activation and failure. Circulation. 1994; 90(1): 234-240, doi: 10.1161/01.cir.90.1.234, indexed in Pubmed: 8026003.

81. Esler M, Rumantir M, Kaye D, et al. The sympathetic neurobiology of essential hypertension: disparate influences of obesity, stress, and noradrenaline transporter dysfunction? Am J Hypertens. 2001; 14(6 Pt 2): 139S-146S, indexed in Pubmed: 11411749.

82. Bianchi G, Fox U, Di Francesco GF, et al. Blood pressure changes produced by kidney cross-transplantation between spontaneously hypertensive rats and normotensive rats. Clin Sci Mol Med. 1974; 47(5): 435-448, indexed in Pubmed: 4611680.

83. Smithwick RH, Thompson JE. Splanchnicectomy for essential hypertension; results in 1,266 cases. J Am Med Assoc. 1953; 152(16): 1501-1504, indexed in Pubmed: 13061307.

84. Staessen JA, Wang J, Bianchi G, et al. Essential hypertension. Lancet. 2003; 361(9369): 1629-1641, doi: 10.1016/S01406736(03)13302-8, indexed in Pubmed: 12747893.

85. Staessen J, Amery A, Fagard R. Isolated systolic hypertension in the elderly. J Hypertens. 1990; 8(5): 393-405, indexed in Pubmed: 2163412. 
86. Persu A, Jin Y, Azizi M, et al. Blood pressure changes after renal denervation at 10 European expert centers. J Hum Hypertens. 2014; 28(3): 150-156, doi: 10.1038/jhh.2013.88, indexed in Pubmed: 24067345.

87. de Jong MR, Hoogerwaard AF, Gal P, et al. Persistent increase in blood pressure after renal nerve stimulation in accessory renal arteries after sympathetic renal denervation. Hypertension. 2016; 67(6): 1211-1217, doi: 10.1161/HYPERTENSIONAHA.115.06604, indexed in Pubmed: 27113046.

88. de Jong MR, Adiyaman A, Gal P, et al. Renal nerve stimulation-induced blood pressure changes predict ambulatory blood pressure response after renal denervation. Hypertension. 2016; 68(3): 707-714, doi: 10.1161/HYPERTENSIONAHA.116.07492, indexed in Pubmed: 27432864.

89. Schurgers LJ, Cranenburg ECM, Vermeer C. Matrix Gla-protein: the calcification inhibitor in need of vitamin $\mathrm{K}$. Thromb Haemost. 2008; 100(4): 593-603, doi: 10.1160/TH08-02-0087, indexed in Pubmed: 18841280.

90. Wei FF, Drummen NEA, Schutte AE, et al. Vitamin K dependent protection of renal function in multi-ethnic population studies. EBioMed. 2016; 4: 162-169, doi: 10.1013/j. ebiom.2016.01.011, indexed in Pubmed: 26981580.

91. Wei FF, Trenson S, Thijs L, et al. Desphospho-uncarboxylated matrix Gla protein is a novel circulating biomarker predicting deterioration of renal function in the general population. Nephrol Dial Transplant. 2017 [Epub ahead of print], doi: 10.1093/ndt/gfx258, indexed in Pubmed: 28992263.

92. Apostolopoulos V, Stojanovska L, Gargosky SE. MUC1 (CD227): a multi-tasked molecule. Cell Mol Life Sci. 2015; 72(23): 4475-4500, doi: 10.1007/s00018-015-2014-z, indexed in Pubmed: 26294353.

93. Zhang ZY, Ravassa S, Pejchinovski M, et al. A urinary fragment of mucin-1 subunit $\alpha$ is a novel biomarker associated with renal dysfunction in the general population. Kidney Int Rep. 2017;
2(5): 811-820, doi: 10.1016/j.ekir.2017.03.012, indexed in Pubmed: 28920100.

94. Nkuipou-Kenfack E, Zürbig P, Mischak H. The long path towards implementation of clinical proteomics: Exemplified based on CKD273. Proteomics Clin Appl. 2017; 11(5-6), doi: 10.1002/prca.201600104, indexed in Pubmed: 28019083.

95. Gu YM, Thijs L, Liu YP, et al. The urinary proteome as correlate and predictor of renal function in a population study. Nephrol Dial Transplant. 2014; 29(12): 2260-2268, doi: 10.1093/ndt/gfu234, indexed in Pubmed: 24981581.

96. Pontillo C, Zhang ZY, Schanstra JP, et al. Prediction of chronic kidney disease stage 3 by CKD273, a urinary proteomic biomarker. Kidney Int Rep. 2017; 2(6): 1066-1075, doi: 10.1016/j. ekir.2017.06.004, indexed in Pubmed: 29130072.

97. Zhang Z, Staessen JA, Thijs L, et al. Left ventricular diastolic function in relation to the urinary proteome: a proof-of-concept study in a general population. Int J Cardiol. 2014; 176(1): 158-165, doi: 10.1016/j.ijcard.2014.07.014, indexed in Pubmed: 25065337.

98. Zhang ZY, Thijs L, Petit T, et al. Urinary proteome and systolic blood pressure as predictors of 5-year cardiovascular and cardiac outcomes in a general population. Hypertension. 2015; 66(1): 52-60, doi: 10.1161/HYPERTENSIONAHA.115.05296, indexed in Pubmed: 26063667.

99. Martin-Lorenzo M, Martinez PJ, Baldan-Martin M, et al. Citric acid metabolism in resistant hypertension: underlying mechanisms and metabolic prediction of treatment response. Hypertension. 2017; 70(5): 1049-1056, doi: 10.1161/HYPERTENSIONAHA.117.09819, indexed in Pubmed: 28874460.

100. Lindhardt M, Persson F, Currie G, et al. Proteomic prediction and Renin angiotensin aldosterone system Inhibition prevention Of early diabetic nephRopathy in TYpe 2 diabetic patients with normoalbuminuria (PRIORITY): essential study design and rationale of a randomised clinical multicentre trial. BMJ Open. 2016; 6(3): e010310, doi: 10.1136/bmjopen-2015-010310, indexed in Pubmed: 26936907.

Cite this article as: Wei F-F, Zhang Z-Y, Huang Q-F, et al. Resistant hypertension. Kardiol Pol. 2018; 76(7): 1031-1042, doi: 10.5603/KP.a2018.0129. 